\title{
Variations in Tropical Cyclone Genesis Factors in Simulations of the Holocene Epoch
}

\author{
ROBERT L. KORTY \\ Department of Atmospheric Sciences, Texas A\&M University, College Station, Texas \\ SuZANA J. CAMARGO \\ Lamont-Doherty Earth Observatory, Columbia University, Palisades, New York \\ JOSEPH GALEWSKY \\ Department of Earth Sciences, University of New Mexico, Albuquerque, New Mexico
}

(Manuscript received 5 January 2012, in final form 12 May 2012)

\begin{abstract}
The thermodynamic factors related to tropical cyclone genesis are examined in several simulations of the middle part of the Holocene epoch when the precession of Earth's orbit altered the seasonal distribution of solar radiation and in one transient simulation of the millennium preceding the industrial era. The thermodynamic properties most crucial for genesis display a broad stability across both periods, although both orbital variations during the mid-Holocene (MH) 6000 years ago (6ka) and volcanic eruptions in the transient simulation have detectable effects. It is shown that the distribution of top-of-the-atmosphere radiation $6 \mathrm{ka}$ altered the Northern Hemisphere seasonal cycle of the potential intensity of tropical cyclones in addition to slightly increasing the difference between middle tropospheric and boundary layer entropy, a parameter that has been related to the incubation period required for genesis. The Southern Hemisphere, which receives more solar radiation during its storm season today than it did 6ka, displays slightly more favorable thermodynamic properties during the MH than in the preindustrial era control. Surface temperatures over the ocean in both hemispheres respond to radiation anomalies more slowly than those in upper levels, altering the thermal stability.

Volcanism produces a sharp but transient temperature response in the last-millennium simulation that strongly reduces potential intensity during the seasons immediately following a major eruption. Here, too, the differential vertical temperature response is key: temperatures in the lower and middle troposphere cool, while those near the tropopause rise. Aside from these deviations, there is no substantial variation in thermodynamic properties over the 1000 -yr simulation.
\end{abstract}

\section{Introduction}

Owing to the limited duration and quality of the instrumental record of global tropical cyclones, geologic proxies of prehistoric storms have emerged as a promising supplementary avenue for insight into how tropical cyclones (TCs) may vary over time. Many different techniques have been developed to infer the presence of past tropical cyclones (see, e.g., Frappier et al. 2007 for a more thorough review), but one particularly useful

Corresponding author address: Robert L. Korty, Department of Atmospheric Sciences, Texas A\&M University, TAMU 3150, College Station, TX 77843-3150.

E-mail: korty@tamu.edu proxy of long-term TC activity is the preserved overwash deposits within backbarrier beach environments (e.g., Liu and Fearn 1993; Donnelly 2005; Donnelly and Woodruff 2007; Woodruff et al. 2008, 2009). These sedimentary records can span several millennia of the middle Holocene (MH) and late Holocene epoch, during which time sea level rise was slow (Lighty et al. 1982) and atmospheric composition was stable (see, e.g., Braconnot et al. 2007a). There are, naturally, many limitations: there is a paucity of suitable cores, they are sporadically dispersed, and they provide a record only of events of sufficient strength or duration to wash over a particular barrier island. Yet, they provide a very long record at a single location, and collectively their common features yield at least some information where 
none would otherwise exist. Compilations have shown that periods of fairly regular deposition over the last 5000 years have been interrupted by intervals with little or no activity (e.g., Donnelly and Woodruff 2007; Lane et al. 2011). Woodruff et al. (2009) speculated that gaps in cores from the western Atlantic, which are anticorrelated with ones from Japan, might be associated with ENSO variability.

While these records provide some insight into particular aspects of the climatology of land-falling events at specific sites, they and related proxies cannot offer information from a storm's journey across open oceans, where it spends nearly all of its lifetime (on average, 180 h, Emanuel 2005). Whatever the source of variability in any particular core, a basic question has yet to be addressed comprehensively: do variations in the climate during the Holocene affect the large-scale environment in ways that might influence TCs?

Broadly speaking, the composition of the atmosphere was stable across the preindustrial Holocene epoch (e.g., Braconnot et al. 2007a), but other aspects of climate forcing varied in ways that could potentially affect the large-scale environment. The precession and rotation of the ellipse of Earth's orbit yield a cycle $(\sim 20000 \mathrm{yr})$ in the date of Earth's closest approach to the sun (e.g., Berger 1978), which in turn leads to substantial variations in the seasonal distribution of solar radiation across the Holocene. Surface temperatures over the last millennium fluctuated even during the centuries preceding the industrial revolution (e.g., Mann et al. 1999), during which time variable solar irradiance and sporadic volcanic activity induced transient and regional deviations (e.g., Jones and Mann 2004). The magnitude of temperature deviations during the last millennium was generally small (a fraction of $1^{\circ} \mathrm{C}$ ), but even slight fluctuations can affect tropical cyclone environmental variables in subtle ways. For example, Elsner and Jagger (2008) presented evidence that interannual solar variability has a detectable effect on tropical cyclone climatology, even though the effects on surface temperature are small.

The thermal structure of the tropical atmosphere plays a fundamental role in establishing the suitability of a region for tropical cyclone genesis. Modern-day observations show that TCs form in regions where thermodynamic soundings are conducive for deep tropospheric convection, have high moisture levels in the middle troposphere, and where vertical shear of the horizontal wind (hereafter, vertical shear) is weak. These fields are generally well correlated with genesis locations, and their variability is useful for diagnosing the effects of large-scale changes caused by external forcing or remote phenomena such as ENSO (Camargo et al. 2007a,b). Output from general circulation models, which are well suited to predicting the evolution of these factors even if their resolution is too coarse to resolve individual cyclones, has been used to investigate the functional dependence of these environmental factors on climate in both warmer future periods (e.g., Vecchi and Soden 2007; Emanuel et al. 2008) as well as past colder ones (Korty et al. 2012). Emanuel (2010) also investigated these properties in reanalysis data from the early twentieth century.

As these and other studies have shown, planetaryscale climate changes can affect the thermodynamic quantities important to genesis. Yet a host of other external variations may also influence the suitability of the large-scale environment for genesis. Paleoclimate simulations of particular segments through the Holocene epoch offer a unique opportunity to examine the effects of several external factors in isolation from changes in greenhouse gas composition, given the long period of stable carbon dioxide $\left(\mathrm{CO}_{2}\right)$ levels between the MidHolocene and beginning of the industrial era.

Here we focus on the response to large-scale variations in radiation during the Holocene. Using the archive of simulations of the Mid-Holocene $(\mathrm{MH})$ period 6000 years ago (6ka) compiled for phase 2 of the Paleoclimate Modelling Intercomparison Project (PMIP2) (Braconnot et al. 2007a,b), we assess how summer and autumn perturbations in incoming solar radiation affect the structure of the large-scale tropical environment and alter properties important for tropical cyclone genesis. During the $\mathrm{MH}$, the greenhouse gas composition of the atmosphere $6 \mathrm{ka}$ was very similar to the preindustrial era: the same amounts of $\mathrm{CO}_{2}(280 \mathrm{ppm})$ and nitrous oxide (270 ppb) existed during both times, though methane was slightly lower $6 \mathrm{ka}(650 \mathrm{ppb})$ than in the preindustrial era (760 ppb) (Otto-Bliesner et al. 2006). But in the MH, Earth's closest approach to the Sun occurred during September, while presently the perihelion occurs in early January; as a result there were substantially higher amounts of top-of-the-atmosphere (TOA) solar radiation during summer and early autumn in the Northern Hemisphere $(\mathrm{NH})$ when the tropical cyclone season peaks there. Conversely, there was much less solar radiation 6ka during the peak months of the Southern Hemisphere ( $\mathrm{SH})$ tropical cyclone season than there is presently.

The output of a recently completed 1000-yr simulation of the last millennium (LM) provides an unusually long record to assess variability in TC genesis factors that arises from forcing independent of orbital and greenhouse gas changes (see Landrum et al. 2012). It also permits us to examine the modeled transient response to volcanic eruptions, which are one of the 
(a) $6 \mathrm{ka}$

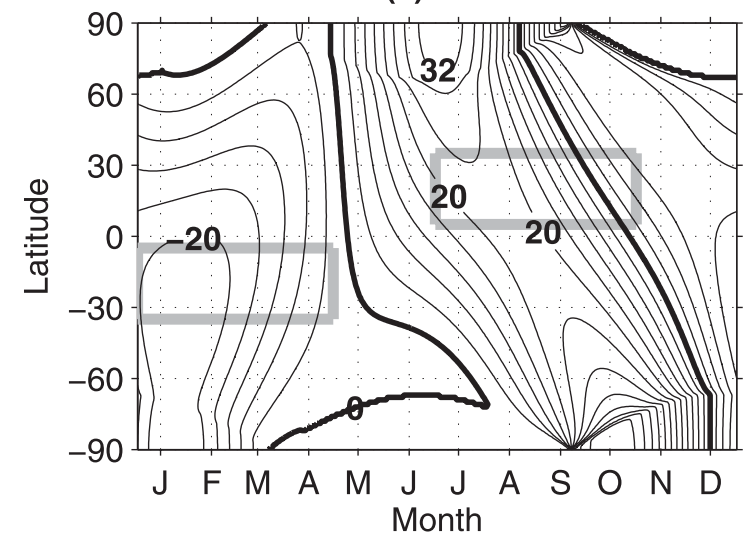

(b) 1 ka

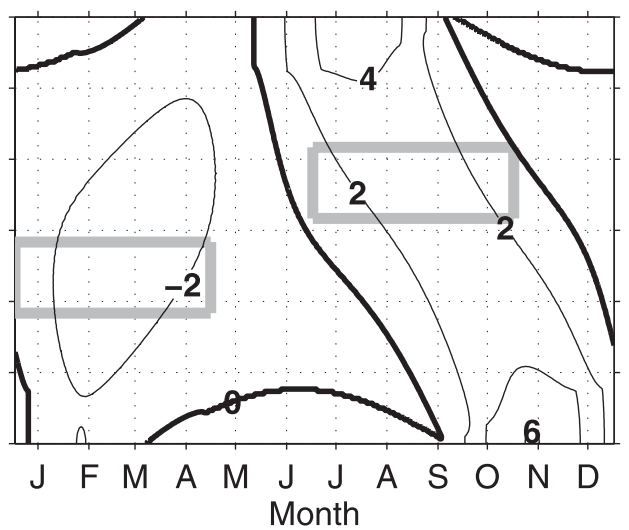

(c) Storm season $\triangle T O A$

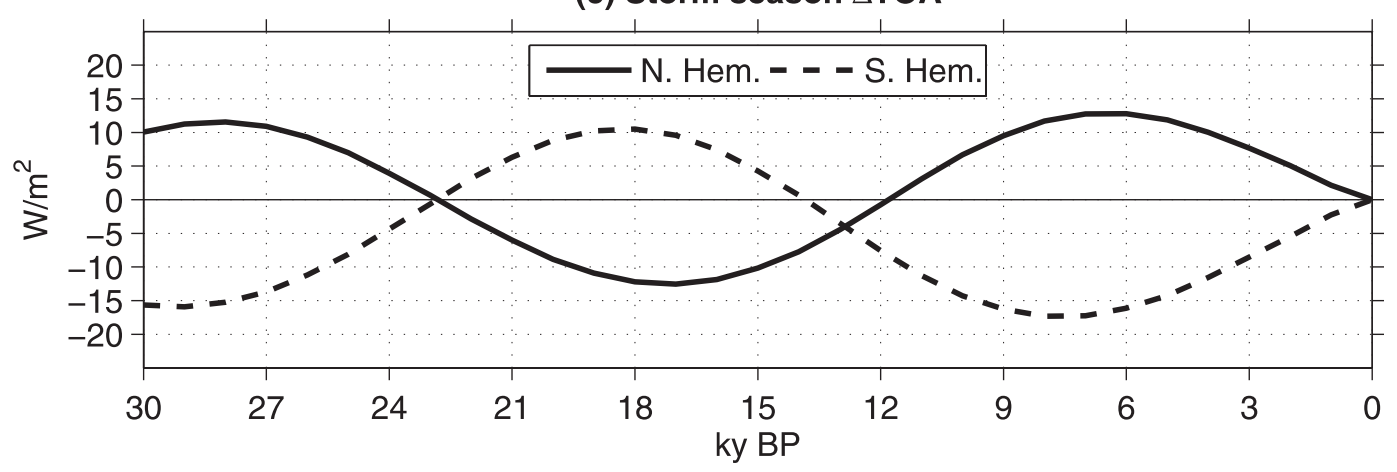

FIG. 1. Change from today's distribution of incoming solar radiation as a function of time of year and latitude at (a) Mid-Holocene and (b) $1 \mathrm{ka}$. Contours are drawn in $4 \mathrm{~W} \mathrm{~m}^{-2}$ intervals in (a) and $2 \mathrm{~W} \mathrm{~m}^{-2}$ intervals in (b). Solid lines indicate higher solar radiation in past periods and dashed contours indicate less; heavy solid line is no change. Gray boxes define storm season and regions of tropical cyclone activity. (c) The 30000 -yr time series of TOA radiation difference between past and today averaged over months and latitudes of $\mathrm{NH}$ (solid) and $\mathrm{SH}$ (dashed).

major external forcings for this period. Volcanism alters the thermal structure of the tropical atmosphere, which could affect the thermodynamic environment for TCs. The solar cycle has the potential to produce a thermal response with a similar vertical structure (yet far weaker in magnitude), but this paleoclimate simulation lacks feedbacks in solar-related ozone changes, which renders it ill-suited for studying any such effects here; we discuss these limitations further in sections 2 and 5.

We present the salient features of the various Holocene simulations in section 2 and review relevant thermodynamic genesis factors in section 3 . In section 4 we present our analysis of how TC genesis factors respond to the MH orbital variations. In section 5 we discuss their variability in the LM simulation, including the transient response to volcanism. We summarize our main findings in section 6 and discuss some implications and challenges for comparisons to "paleotempestology" studies.

\section{Overview of Mid-Holocene and last millennium simulations}

\section{a. Mid-Holocene}

By 6ka, major ice sheets from the Last Glacial Maximum (LGM) had retreated and the composition of the atmosphere was broadly similar to recent times: levels of $\mathrm{CO}_{2}$ were $280 \mathrm{ppm}$, where they would remain through the preindustrial era. The major difference was the date of the perihelion owing to the precession of Earth's orbit; as can be seen in Fig. 1a, there was substantially more TOA solar radiation during the NH TC season 6ka than there is today, while the SH season had much less. ${ }^{1}$ The sign of these deviations persisted throughout the

\footnotetext{
${ }^{1}$ We define the storm season to be the four most active months: July-October in the NH and January-April in the SH, though these results are qualitatively insensitive to other suitable choices (e.g., December-March in the SH).
} 
TABLE 1. Coupled ocean-atmosphere model members of the PMIP2 archive included in our analysis. The atmospheric data resolution included in the archive is shown, but all data were interpolated onto a common $128 \times 64$ longitude-latitude grid for comparison and ensemble mean calculations. Only models without flux adjustments and with standard tropospheric vertical resolution were included; the 6ka ensemble includes 10 members. Further details are available in Braconnot et al. (2007a) and in the database archive (see online at http://pmip2.1sce.ipsl.fr).

\begin{tabular}{lr}
\hline \hline \multicolumn{1}{c}{ Model } & Lon $\times$ lat $\times$ levels \\
\hline Community Climate System Model, version 3 (CCSM3) & $128 \times 64 \times 17$ \\
Commonwealth Scientific and Industrial Research Organisation Mark version 3L-1.0 (CSIRO Mk3L-1.0) & $64 \times 56 \times 17$ \\
ECHAM5-Max Planck Institute Ocean Model (MPI-OM1) & $96 \times 48 \times 16$ \\
Flexible Global Ocean-Atmosphere-Land System Model gridpoint version 1.0 (FGOALS-g1.0) & $128 \times 60 \times 17$ \\
Fast Ocean Atmosphere Model (FOAM) & $48 \times 40 \times 17$ \\
Goddard Institute for Space Studies Model E (GISS-modelE) & $72 \times 45 \times 17$ \\
University of Bristol (UBRIS)-third climate configuration of the Met Office Unified Model (HadCM3M2) & $96 \times 73 \times 15$ \\
L'Institut Pierre-Simon Laplace Coupled Model, version 4-V1-MR (IPSL CM4-V1-MR) & $96 \times 72 \times 17$ \\
Model for Interdisciplinary Research on Climate 3.2 (MIROC3.2) & $128 \times 64 \times 17$ \\
Meteorological Research Institute Coupled General Circulation Model, version 2.3nfa (MRI CGCM2.3nfa) & $128 \times 64 \times 17$ \\
\hline
\end{tabular}

Holocene, but the anomalies have been declining in magnitude and the peak deviations have shifted progressively later in the calendar with each passing millennia since 6ka (Figs. 1b,c). The perihelion occurred during September 6ka and advanced to mid-December by $1 \mathrm{ka}$ (the closest approach to the sun moves forward one calendar day approximately every 57 years).

We use 10 separate atmosphere-ocean coupled models (none of which use flux adjustments) to define an ensemble of MH simulations and average over the output from these individual members to form an ensemble mean for 6ka. These are compared to an ensemble average of the preindustrial era ( $0 \mathrm{ka}$ ) formed using the same 10-member (preindustrial) control simulations [see Table 1 for details of the ensemble membership; also see Braconnot et al. (2007a) for further model details]. The model output was generated for phase 2 of the Paleoclimate Modelling Intercomparison Project, which is archived online (see http://pmip2.lsce.ipsl.fr; also, Braconnot et al. 2007a). The calculation of $V_{\mathrm{PI}}$ requires a sounding with temperature and humidity data with vertical resolution at least as high as mandatory (standard) pressure levels all the way to the lower stratosphere $(\sim 70 \mathrm{hPa}$ in the present climate), which limits our analysis to the portion of the PMIP2 archive containing data at this resolution. Though the archive contains some output at high temporal resolution, many of the individual models offer only a small selection of two-dimensional fields at daily or monthly frequencies.

The portion of the archive that contains sufficient vertical resolution is averaged into a climatological seasonal cycle: Korty et al. (2012) reported that the effects of this type of averaging on the genesis parameters are small. Although daily and interannual variability is lost, absent a suitable observational record from past millennia against which one could compare such model-generated variability, we do not view this as a limitation for our present purposes. The individual genesis factors were computed from each model's wind, temperature, and humidity data on their native grid; the factors were then linearly interpolated onto a common 128 by 64 longitude-latitude grid to compute ensemble means. The $\mathrm{MH}$ ensemble contains 10 member simulations and its average is compared to an ensemble mean formed from the same 10-model preindustrial simulations.

\section{b. Last millennium}

For phase 3 of the Paleoclimate Modelling Intercomparison Project (PMIP3), modeling groups were requested to perform a simulation of the 1000 years preceding the industrial era and their own simulations of the late nineteenth and twentieth centuries. These LM runs span the years $850-1850$ and will be released with phase 3 of PMIP. Here we use a single recently completed simulation of this period from the Community Earth System Model (CESM) (Landrum et al. 2012) to begin exploring some of the large-scale influences that can be captured by output from this long time series.

By A.D. 850 the perihelion had progressed to midDecember and continued to advance toward its present early-January position in the calendar over the ensuing centuries. Figure 1 shows that the large amplitude perturbations in TOA radiation present during the $\mathrm{MH}$ (Fig. 1a) had largely faded away by 1000 years ago (Fig. 1b), with the magnitude of tropical deviations diminished to about one-tenth of their MH values. This slow drift toward lower solar irradiance during NH TC seasons and the upward trend in during the $\mathrm{SH}$ season are captured in the total solar irradiance (TSI) used to force the LM simulation; Fig. 2 shows the time series for these seasons and latitudes. Superimposed on top of the long-term drift are small amplitude deviations caused by 

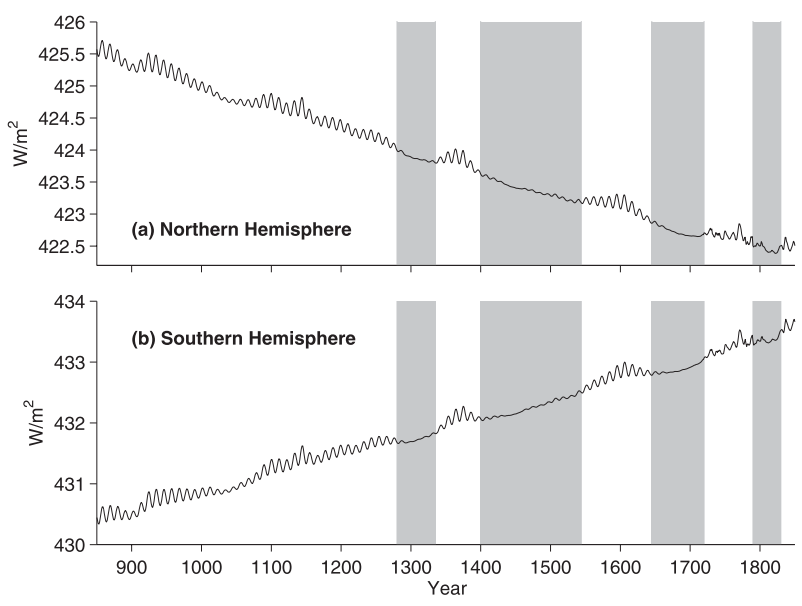

FIG. 2. Time series of total solar irradiance over the course of the last millenium simulation for (a) JASO between $10^{\circ}$ and $20^{\circ} \mathrm{N}$ latitude and (b) JFMA between $10^{\circ}$ and $20^{\circ} \mathrm{S}$ latitude. The years with low amplitude or absent solar cycles surrounding the Wolf, Spörer, Maunder, and Dalton minima are shaded gray.

solar cycles; these were added from reconstructions back to the seventeenth century with a synthetic, regular, 11-yr cycle imposed on earlier centuries (see Schmidt et al. 2011; Landrum et al. 2012 for further details). The welldocumented periods of solar activity minima (e.g., Eady 1976) are also incorporated in the time series (see Fig. 2 ). The concentrations of long-lived greenhouse gas concentrations are broadly flat across the pre-industrial Holocene until 1800, although the prescribed values vary slightly owing to natural feedbacks in carbon and nitrogen cycles (Landrum et al. 2012).

Although the simulation incorporates forcing by TSI, there are no solar-related ozone changes; as we discuss further in section 5, this renders the simulation ill-suited to properly investigate any effects of the solar cycle on the thermodynamics of TC genesis factors, as the temperature response differs in amplitude and structure in crucial ways from those seen in contemporary observations. Maxima in the solar cycle raise TSI, but the effects are not uniform across all wavelengths: the short ultraviolet wavelengths are most strongly affected (Gray et al.2010), which makes the response of tropopause and lower stratospheric temperatures quite sensitive to some feedbacks missing in the LM simulation.

Yet the LM simulation includes still other forcings that can affect the thermodynamic response. Volcanic emissions, whose time series was inferred from the ice-core-based index of Gao et al. (2008), are incorporated as a function of latitude, altitude, and month. Three particular eruptions appear to be larger than any others since 1850: one in year 1258 (unknown origin), which injected total sulfate aerosols into the stratosphere in excess of $250 \mathrm{Tg}$, the eruption of Kuwae (1452), and
Tambora (1815). We investigate how the effects of these strong eruptions on the thermal structure of the tropical troposphere manifest themselves in properties important to TC genesis. The responses are sharp but transient: they are large in amplitude but generally fade away within $2 \mathrm{yr}$.

\section{Tropical cyclone genesis factors}

In this section we briefly review the large-scale environmental conditions that are most conducive for TC formation. For a more comprehensive review of the value of particular thermodynamic factors and the construction of various genesis potential (GP) indices, see discussions in Nolan (2011) and Korty et al. (2012).

Both warm surface waters and tropospheric thermal profiles conducive to moist convection have long been recognized to be nearly omnipresent at the time of genesis (Gray 1968). Following the development of potential intensity theory (Emanuel 1986), we now view these in a united framework: only regions that have both ocean-to-atmosphere fluxes and thermal stability profiles that support deep moist convection are able to yield and sustain strong TCs. There is nothing particularly special about any particular sea surface temperature, but regions that satisfy these requirements in the present climate are generally collocated with locations where SST $>26^{\circ} \mathrm{C}$. In other climates, however, these requirements will be met at locations that correspond to a different range of SST (e.g., Emanuel 1987; Royer et al. 1998; Vecchi and Soden 2007; Korty et al. 2012). Thus, while a principal use of potential intensity is to calculate the maximum wind speed permissible by the thermodynamic environment, the quantity is also useful in genesis studies in a diagnostic role: it is high only where the environment supports the existence of TCs in the first place.

Potential intensity $\left(V_{\mathrm{PI}}\right)$ can be calculated from vertical thermodynamic soundings (Bister and Emanuel 2002); it is a function of SST and temperatures at the level of convective outflow $\left(T_{o}\right)$, which is determined by the level of neutral buoyancy:

$$
V_{\mathrm{PI}}=\sqrt{\frac{C_{k}}{C_{d}} \frac{\mathrm{SST}-T_{o}}{T_{o}}\left(k_{0}^{*}-k\right) .}
$$

Potential intensity also depends on the ratio of the exchange coefficients for enthalpy and $\operatorname{drag}\left(C_{k} / C_{d} \approx 1\right)$ and the thermodynamic disequilibrium at the surface, measured by the difference in the marine boundary layer enthalpy $k$ and the value a parcel would have if saturated at the $\operatorname{SST}\left(k_{0}^{*}\right)$. Because temperatures in the marine boundary layer are often very nearly equal to the 

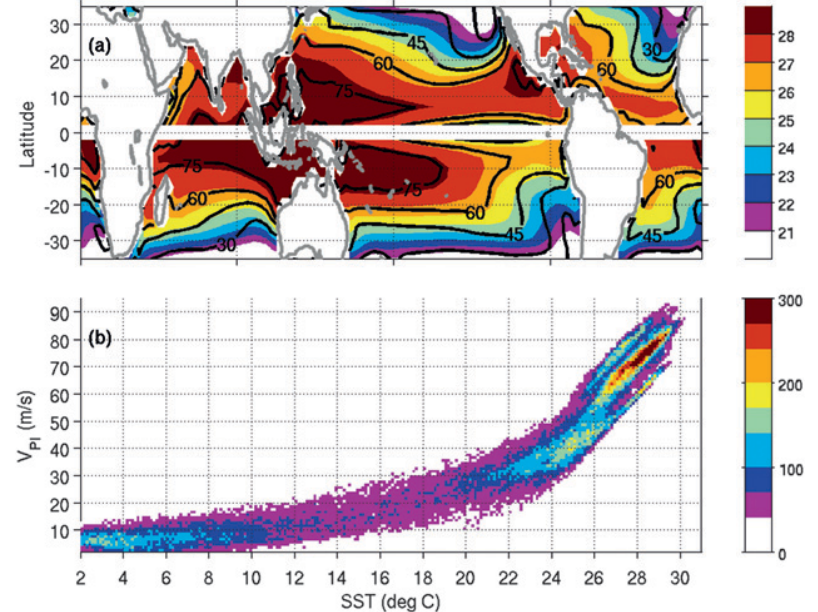

FIG. 3. (a) Storm-season (JASO NH; JFMA SH) ensemble mean $0 \mathrm{ka}$ potential intensity (black contours, $\mathrm{m} \mathrm{s}^{-1}$ ) and storm-season ensemble mean SST (colors, ${ }^{\circ} \mathrm{C}$ ). (b) Histograms of SST $\left({ }^{\circ} \mathrm{C}\right)$ and potential intensity $\left(\mathrm{m} \mathrm{s}^{-1}\right)$ for the $0 \mathrm{ka}$ ensemble. Data were binned by intervals $1 \mathrm{~m} \mathrm{~s}^{-1}\left(V_{\mathrm{PI}}\right)$ and $0.125^{\circ} \mathrm{C}$ (SST) wide. The total number of grid cells from all 10 models for all 12 months are counted and plotted; some bins exceeded 300 grid cells, but the color scale is clipped there to retain resolution for lower counts.

$\mathrm{SST}, k_{0}^{*}-k$ is nonzero principally owing to the fact that marine boundary layers are generally subsaturated.

Figure 3a shows the storm-season ensemble mean of the preindustrial-era control simulation potential intensity (black contours) on top of the storm season and ensemble mean SST. The regions of highest $V_{\mathrm{PI}}$ occur in the deep tropics, where water temperatures are also highest. Yet the correlation between the two belies a more complicated relationship between $V_{\mathrm{PI}}$ and the thermodynamic environment of the full troposphere. Figure $3 \mathrm{~b}$ shows the joint distribution of $V_{\mathrm{PI}}$ with SST. The highest $V_{\mathrm{PI}}$ lie in regions where convection can penetrate highest, which is also where SST is warmest. Yet, there is not a singular relationship between $V_{\mathrm{PI}}$ and SST: for example, at locations in which SST is $27^{\circ} \mathrm{C}, V_{\mathrm{PI}}$ values anywhere in the range between 50 and $80 \mathrm{~m} \mathrm{~s}^{-1}$ might be commonly found.

Potential intensity is more clearly bifurcated between high values $\left(V_{\mathrm{PI}}\right.$ that exceed $\left.\sim 55 \mathrm{~m} \mathrm{~s}^{-1}\right)$ and low ones ( $V_{\mathrm{PI}}$ below $\sim 55 \mathrm{~m} \mathrm{~s}^{-1}$ ) by the structure of the atmospheric sounding, which is related to its convective available potential energy (Bister and Emanuel 2002). The storm-season ensemble mean of the level of neutral buoyancy (LNB) for parcels lifted from the surface and $V_{\mathrm{PI}}$ are shown in Fig. 4a (as in Fig. 3, these are preindustrial-era control values). The joint distribution of LNB and $V_{\mathrm{PI}}$ is shown in Fig. 4b; values of $V_{\mathrm{PI}}>$ $55 \mathrm{~m} \mathrm{~s}^{-1}$ occur only where deep convection is possible. The sharpness of the boundary separating regions in which deep convection is possible from those in which it
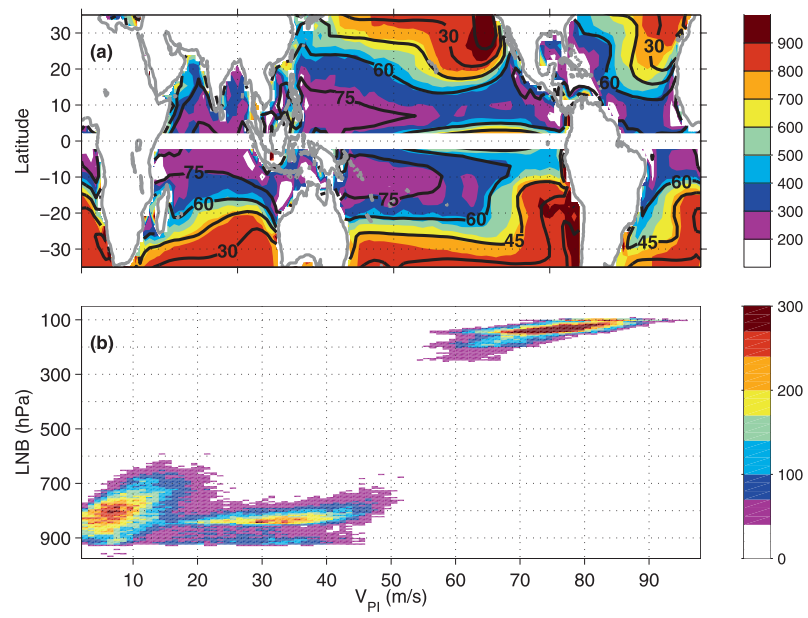

FIG. 4. (a) As in Fig. 3a but with colored contours of the stormseason ensemble mean level of neutral buoyancy (LNB, hPa). (b) Histograms of potential intensity $\left(\mathrm{m} \mathrm{s}^{-1}\right)$ and LNB (hPa) for the $0 \mathrm{ka}$ ensemble. Data were binned by intervals $1 \mathrm{~m} \mathrm{~s}^{-1}\left(V_{\mathrm{PI}}\right)$ and $5 \mathrm{hPa}$ (LNB) wide. Like Fig. 3b, some bins exceeded 300 grid cells, but the color scale is clipped there to retain resolution for lower counts.

is not is obscured in Fig. 4a by both its seasonal movement and the averaging over 10 different models. LNB between 300 and $600 \mathrm{hPa}$ are rare, and in any one month and in any single model, the jump from regions that support deep convection to those with soundings that trap rising parcels at the top of the boundary layer is often quite abrupt. This boundary is often collocated near the position of the $26^{\circ} \mathrm{C}$ isotherm in the present climate, but its correlation to SST differs in others (q.v. Royer et al. 1998; Korty et al. 2012).

In addition to its thermal structure, other aspects of the large-scale tropical atmosphere are important to developing systems. Burgeoning TCs profit from regions with high relative humidity $(\mathrm{RH})$ in the middle troposphere, as this reduces the detrimental effects of convective downdrafts on genesis. Downdrafts send subsaturated, low entropy air into the boundary layer, and if strong enough, they can overwhelm the inflow of moist, high entropy air that feeds the convection in a nascent system. Persistent convection must saturate the column so that moist boundary layer inflow and deep vertical convection (e.g., Nolan 2011) can be maintained. Thus, incipient systems benefit from higher humidity levels, which reduce the entropy deficits that must be overcome. ${ }^{2}$

Axisymmetric hurricane models (e.g., Emanuel 1989, 1995) have shown that the magnitude of the entropy

\footnotetext{
${ }^{2}$ Further evidence of the importance of this process can be inferred by contrasting the ease with which idealized simulations of dry atmospheres can spawn dry analogs of tropical cyclones with the time required for genesis in moist ones (Mrowiec et al. 2011).
} 
deficit between boundary layer and midtropospheric air compared to the strength of surface fluxes is related to the length of time required for the spinup process. It is a function of both $\mathrm{RH}$ and temperature, and for this reason it has proven to be a valuable parameter for comparing relevant humidity levels between different climate states (Emanuel et al. 2008; Emanuel 2010; Rappin et al. 2010; Korty et al. 2012). This quantity $(\chi)$ is defined as

$$
\chi=\frac{s_{b}-s_{m}}{s_{0}^{*}-s_{b}},
$$

where $s_{b}, s_{m}$, and $s_{0}^{*}$ are the moist entropies ${ }^{3}$ of the boundary layer, middle troposphere (e.g., $600 \mathrm{hPa}$ ), and the saturation entropy at the sea surface, respectively. Because the tropical atmosphere is to first-order nearly neutral with respect to moist convection, lapse rates are approximately moist adiabatic (e.g., $\mathrm{Xu}$ and Emanuel 1989; Korty and Schneider 2007). Thus, the boundary layer entropy in tropical regions is approximately equal to the saturation entropy of the troposphere above it: $s_{b} \approx s^{*}$. With this approximation, the numerator of (2) is approximately equal to the midtropospheric saturation entropy deficit, $s^{*}-s_{m}$. The entropy deficit will change with temperature even if $\mathrm{RH}$ remains constant.

While general circulation models are too coarse to resolve the features central to genesis and maintenance of actual tropical cyclones, they are by design able to predict the large-scale environment that spawns them. We assess how each of these factors is individually affected by changes in the thermal structure of the tropical atmosphere over the Holocene, whatever the source of the variability. These factors have been successfully combined into genesis potential indices, and we use these techniques to summarize the collective effects in our analysis here.

\section{Genesis factors in the Mid-Holocene}

Tropical cyclone genesis factors respond to the seasonal perturbations in the top-of-the-atmosphere (TOA)

\footnotetext{
${ }^{3}$ Moist entropy is proportional to the natural logarithm of equivalent potential temperature $\theta_{e}$. The precise definition we use to calculate $s$ is given by Emanuel (1994, p. 120), which depends on water vapor mixing ratios $r$, relative humidity (hence, vapor pressure $e$ ), and latent heat of vaporization $L$, which vary slightly with temperature. Following the technique outlined in Korty and Schneider (2007), we first compute the vapor pressure and effective latent heat, using the relations of Simmons et al. (1999). These relations are based on saturation over ice and sublimation for temperatures colder than $-23^{\circ} \mathrm{C}$, on saturation over liquid water and vaporization for temperatures above $0^{\circ} \mathrm{C}$, and on quadratic interpolations for temperatures in between.
}
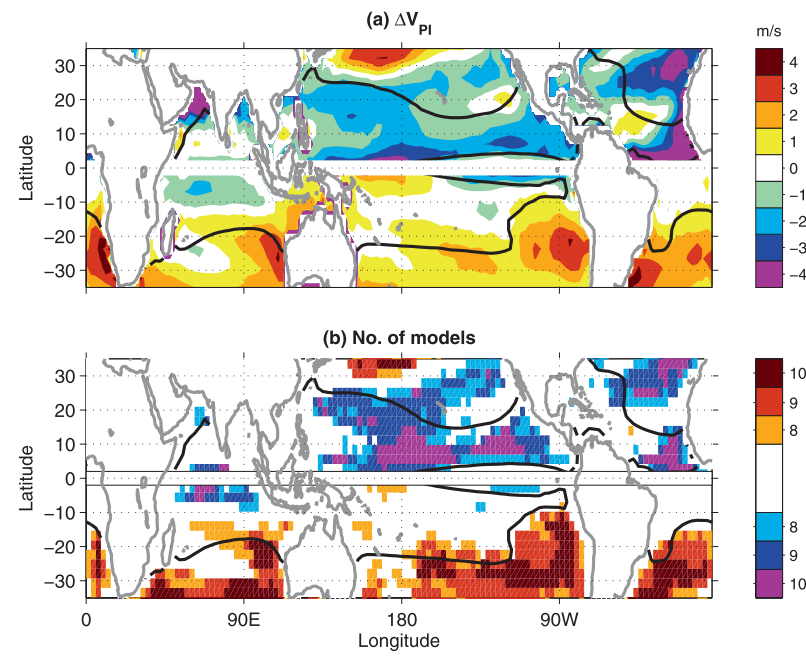

FIG. 5. (a) Difference in storm-season ensemble mean potential intensity between $6 \mathrm{ka}$ and $0 \mathrm{ka}$ (colors, $\mathrm{m} \mathrm{s}^{-1}$ ) with the $55 \mathrm{~m} \mathrm{~s}^{-1}$ contour overlayed in black for reference. (b) Number of ensemble members that agree with sign of change in ensemble mean shown in (a). Areas in blue and purple have 8 or more of the 10 members concurring that potential intensity was lower $6 \mathrm{ka}$; areas in orange or red have 8 or more members concurring that $6 \mathrm{ka}$ potential intensity was higher.

solar radiation caused by variations in Earth's orbit during the $\mathrm{MH}$. We examine the response of several thermodynamic properties important to tropical cyclone genesis over the peak of each storm season in each model and average results to form a multimodel ensemble mean, which is presented here. In all figures showing seasonally averaged data, we define the storm season to be July-October (JASO) in the NH and January-April (JFMA) in the $\mathrm{SH}$, which corresponds to four of the most active months in each hemisphere in the present day. (As will be shown below, these also have the highest genesis potential in both Mid-Holocene and preindustrial-era control simulations.) Alternate suitable definitions of storm season, for example, defining the $\mathrm{SH}$ season to be December-March or averaging over three-month intervals, do not alter qualitatively the findings reported here.

\section{a. Tropical cyclone potential intensity}

With perihelion occurring during September 6ka, TOA radiation was substantially higher during summer and autumn months in the NH. The effects of these changes on $V_{\mathrm{PI}}$ are reported in Fig. 5a, which shows the difference in the 10-member ensemble means between 6ka and 0ka during peak months of each hemisphere's storm season. Despite the higher JASO radiation 6ka in the $\mathrm{NH}$, the $V_{\mathrm{PI}}$ declines in most places, and there is broad agreement in this sign change among the individual ensemble members (Fig. 5b). The decreases in 
$V_{\mathrm{PI}} 6 \mathrm{ka}$ in the $\mathrm{NH}$ are larger during August than during October, by which point the sign of the change has become positive in much of the Indian and Atlantic Oceans and the negative deviation is diminished in amplitude through most of the Pacific (not shown). Conversely, the tropics in the $\mathrm{SH}$ received less TOA radiation $6 \mathrm{ka}$ than in $0 \mathrm{ka}$ during JFMA, but $V_{\mathrm{PI}}$ increases south of $20^{\circ} \mathrm{S}$, with strong agreement among the individual models; at $\mathrm{SH}$ latitudes closer to the equator, where significant values of $V_{\mathrm{PI}}$ are most likely to be found, the differences are smaller in amplitude, and there is little agreement on even their sign. The dominant sign of the change in $V_{\mathrm{PI}}$ is opposite that of the TOA perturbation in both hemispheres, a result that is robust across the ensemble membership (Fig. 5b).

In these simulations, the storm season average SST in regions that spawn tropical cyclones is very similar in both preindustrial era and 6ka experiments (differences between the two periods are less than $0.5^{\circ} \mathrm{C}$ at most points). Thus, the key to understanding why $V_{\mathrm{PI}}$ changes are opposite to the sign of the TOA radiation anomaly lies in the thermal stability of the tropical troposphere. Figure 6 examines the temporal and vertical variations between $10^{\circ}$ and $20^{\circ} \mathrm{N}$ over both land and ocean. TOA radiation anomalies become positive by early May and peak during August (Fig. 6a), but temperatures lag several months behind, particularly in the marine boundary layer. Upper-tropospheric warming occurs during the peak of the storm season above ocean surfaces that are little changed (Fig. 6b), which leads to reductions in $V_{\mathrm{PI}}$ in the $\mathrm{NH}$. Over land (Fig. 6c), increased convection over the Sahel region of Africa (Braconnot et al. 2007b) drives mean lapse rates toward moist adiabatic profiles 6ka (hot surfaces with lowertropospheric lapse rates nearly dry adiabatic occur more frequently here at $0 \mathrm{ka}$ ). This increased convection and its associated increase in cloudiness and precipitation drives surfaces temperatures down $6 \mathrm{ka}$ near the surface (Otto-Bliesner et al. 2006), while upper-tropospheric temperatures increase as a result of convective neutralization. Yet, the total heat content over land rises substantially in response to the TOA radiation increases; this can be better seen by comparing changes in moist entropy $s$, which is proportional to the logarithm of $\theta_{e}$ (Fig. 6d). Local surface warming can cause upperlevel temperatures to rise across great distances in the tropics, as occurs during El Niño (e.g., Tang and Neelin 2004; Lintner and Chiang 2007).

The temperature structure that results from the TOA radiation perturbations implies that the $\mathrm{NH}$ storm season $6 \mathrm{ka}$ would have occurred over an ocean whose SST differed little from 0ka but below an atmosphere that was warmer aloft. In the $\mathrm{SH} V_{\mathrm{PI}}$ was little different from $0 \mathrm{ka}$, as
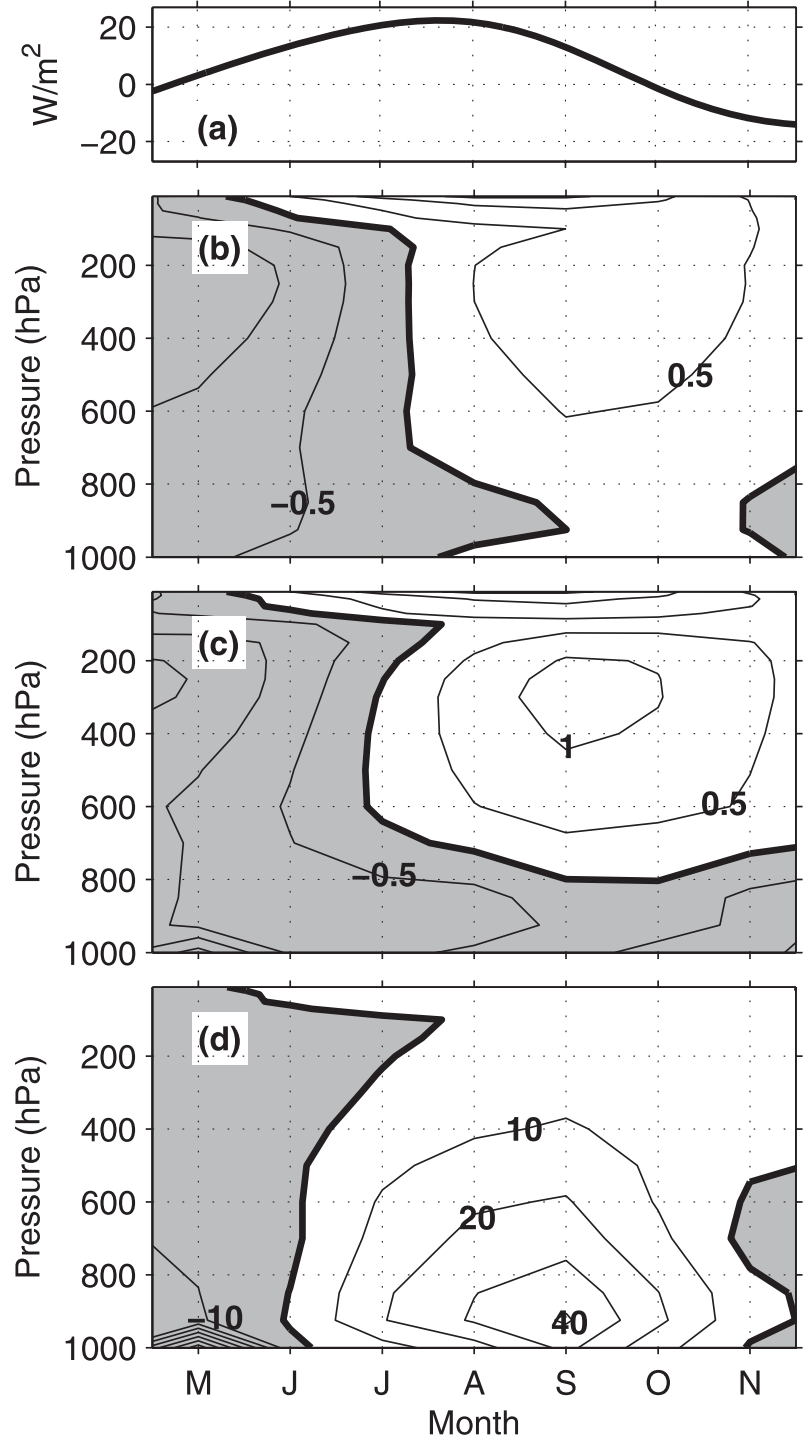

FIG. 6. (a) Time series of 6ka TOA radiation anomalies averaged between $10^{\circ} \mathrm{N}$ and $20^{\circ} \mathrm{N}$. (b) Time series of mean vertical temperature $\left({ }^{\circ} \mathrm{C}\right)$ differences between $6 \mathrm{ka}$ and $0 \mathrm{ka}$ at all ocean points between $10^{\circ}$ and $20^{\circ} \mathrm{N}$. (c) As in (b) but for land points. (d) As in (c) but for moist entropy $s\left(\mathrm{~J} \mathrm{~kg}^{-1} \mathrm{~K}^{-1}\right)$.

both surface and tropospheric temperatures were cooler 6ka. Where Southern Hemisphere oceans cooled less than the atmosphere above (e.g., south of $\left.20^{\circ} \mathrm{S}\right), V_{\mathrm{PI}}$ was higher $6 \mathrm{ka}$; here comparatively high surface temperatures and low convective outflow temperatures maximize $V_{\mathrm{PI}}$, though at these subtropical and middle latitudes $V_{\mathrm{PI}}$ is generally insignificant $\left(<50 \mathrm{~m} \mathrm{~s}^{-1}\right)$ in both periods.

\section{b. Wind shear and tropospheric moisture content}

Wind shear, which we define here as the magnitude of the vector difference in winds between 200 and $850 \mathrm{hPa}$, is generally small in the regions prone to TCs and higher 

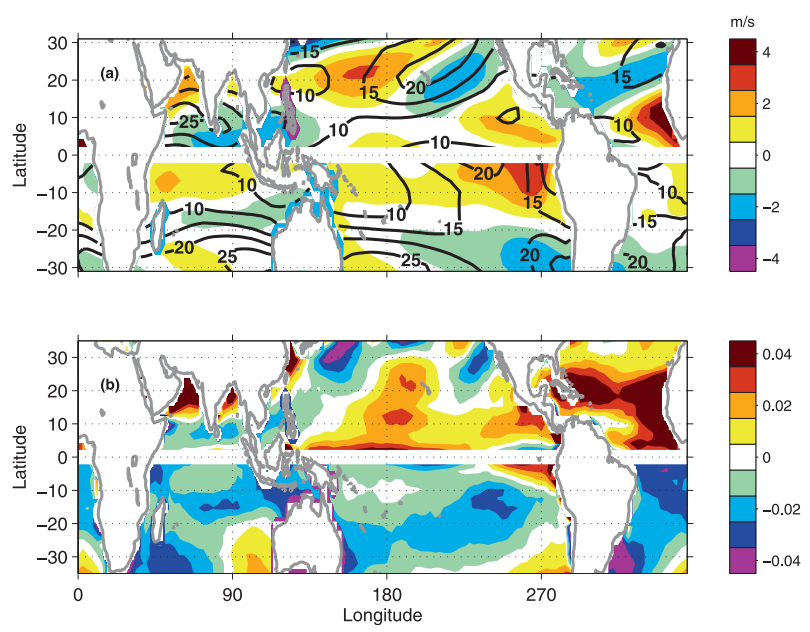

FIG. 7. (a) Magnitude of vector difference between 200-hPa and 850-hPa horizontal winds (black) for storm-season ensemble mean $0 \mathrm{ka}$ and difference in the magnitude of 200-850-hPa wind shear vector between $6 \mathrm{ka}$ and 0ka (colors). (b) Ensemble and stormseason mean difference in nondimensional entropy parameter $\chi$ between $6 \mathrm{ka}$ and $0 \mathrm{ka}$.

at the subtropical margins of genesis regions; Fig. 7a shows the ensemble mean for each hemisphere's storm season at $0 \mathrm{ka}$ in black. The position of the higher values that begin near Hawaii and run northeastward shifts slightly northwest at $6 \mathrm{ka}$, resulting in a dipole pattern in change in shear (color). In the western Atlantic, where shear is weak at $0 \mathrm{ka}$, the magnitude declines further at $6 \mathrm{ka}$. In the $\mathrm{SH}$ season there is an increase in the eastern Pacific south of the equator, but $V_{\mathrm{PI}}$ here is low (see Fig. 3a) and genesis does not occur here in the present climate; elsewhere in the $\mathrm{SH}$ wind shear differences between $6 \mathrm{ka}$ and $0 \mathrm{ka}$ are small in amplitude.

Although an environment with low vertical wind shear has long been known to favor genesis (e.g., Gray 1968; DeMaria 1996), several recent papers have shown that high shear is particularly problematic when the air surrounding the storm is particularly dry. The product of wind shear and a measure of midlevel dryness [such as an entropy deficit, Tang and Emanuel (2010)] is an important predictor of how long the genesis process will take; if too large, genesis is likely to fail (Rappin et al. 2010). Regions with both low wind shear and high midlevel entropy content (i.e., those closer to saturation) are far more favorable for genesis than other areas that offer only one condition or the other.

As discussed in the previous section, JASO warming of the midtroposphere outpaces that of the boundary layer over the oceans, which leads to a small, yet widespread, increase in the temperatures and entropy content of the middle troposphere. Differences in boundary layer entropy between $6 \mathrm{ka}$ and $0 \mathrm{ka}$ are nearly zero across the western North Pacific and are generally small over other oceans, except in the eastern tropical Atlantic where easterly flow carries high entropy air from the moister atmosphere over Africa 6ka. The difference in $\chi$ between 6ka and 0ka is shown in Fig. 7b. ${ }^{4}$ In the NH the entropy parameter is higher $6 \mathrm{ka}$ in much of the tropical central and eastern Pacific and throughout the Atlantic, but the change is mixed in the far western Pacific and Indian Oceans. The increased values of $\chi$ were augmented in the central Pacific and western Atlantic by lower values of midlevel $(600 \mathrm{hPa})$ relative humidity $6 \mathrm{ka}$ than $0 \mathrm{ka}$ (not shown), a pattern that accompanies a shift in convection toward the warmer continental locations. In the SH storm season $6 \mathrm{ka}$, humidity was higher over the oceans and temperatures at midlevels were lower, yielding smaller entropy deficits and lower values of $\chi$.

\section{c. Genesis potential and the seasonal cycle}

The amplitudes of the changes in each of the genesis factors reported in the previous section are generally smaller 6ka than at the LGM (Korty et al. 2012). Nevertheless, they amount to a notable fraction $(\sim 5 \%-$ $10 \%)$ of the original values of the parameters in many areas of the western and eastern North Pacific as well as the $\mathrm{SH}$. Both potential intensity $V_{\mathrm{PI}}$ and $\chi$ were less favorable $6 \mathrm{ka}$ in the $\mathrm{NH}$ season while they were more favorable in the $\mathrm{SH}$, as changes at the surface lag the thermal response of the free troposphere to TOA radiation deviations. During JFMA, the lagged surface response leaves conditions in the $\mathrm{SH}$ relatively mild; strong surface fluxes are able to supply a cooler atmosphere aloft with ample moisture, fueling lower $\chi$ and raising $V_{\mathrm{PI}}$ (though as noted earlier, many of these changes in the Southern Hemisphere occur poleward of tropical cyclone development regions).

Combining the individual metrics in a genesis potential index (GP) has proven to be a useful way to summarize the combined effects of changes in individual factors (e.g., Camargo et al. 2007b; Emanuel et al. 2008; Korty et al. 2012). There are several variants of GP, and some of the recent development was reviewed in Korty et al. (2012); we use the same formulation here:

$$
\mathrm{GP}=\frac{a\left[\min \left(|\eta|, 4 \times 10^{-5}\right)\right]^{3}\left[\max \left(V_{\mathrm{PI}}-35,0\right)\right]^{2}}{\chi^{4 / 3}\left[25+V_{\text {shear }}\right]^{4}},
$$

where $a$ is a normalizing coefficient, $\eta$ is the absolute vorticity, and all other variables are defined above. This

\footnotetext{
${ }^{4}$ We evaluate middle-tropospheric entropy using 600-hPa data and boundary layer entropy using $925 \mathrm{hPa}$. Surface saturation entropy is calculated from the SST and surface pressure.
} 

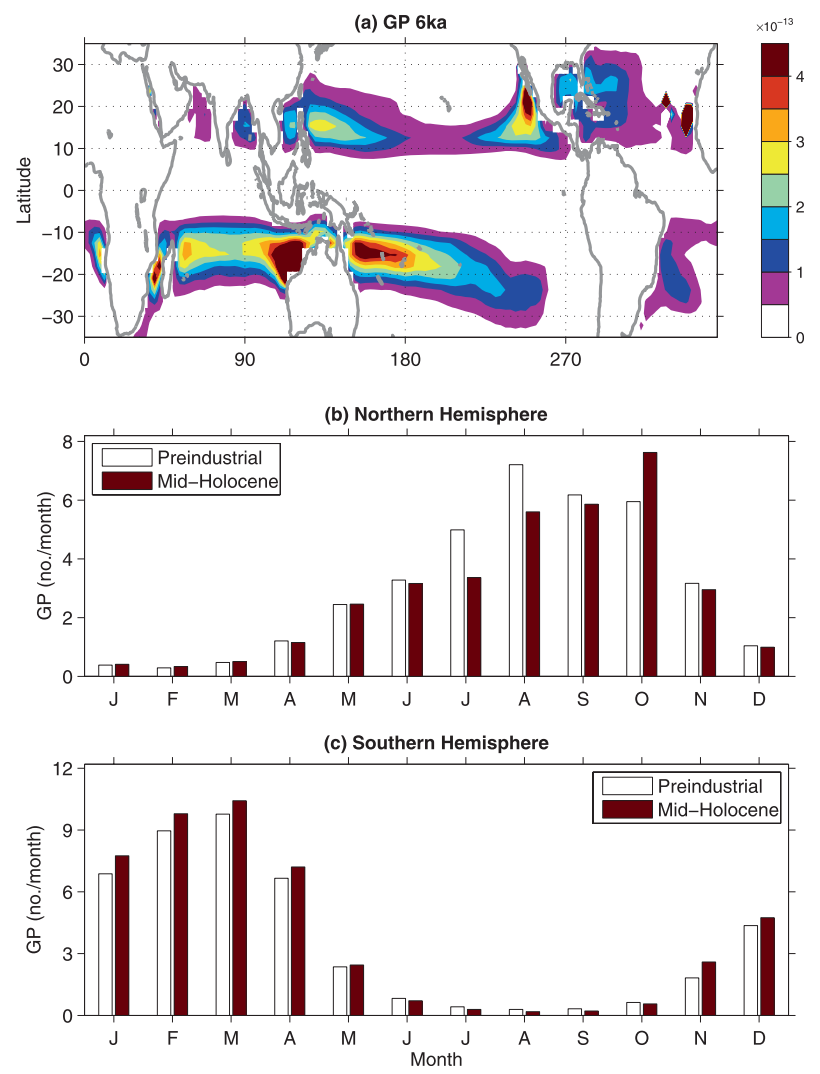

FIG. 8. (a) Storm-season ensemble mean genesis potential 6ka (units are number of events $\mathrm{m}^{-2}$ month $^{-1}$ ). (b) Seasonal cycle of $\mathrm{NH}$ genesis potential as a function of month for 0ka (white) and 6ka (dark red); units are number of events per month. (c) As in (b) but for $\mathrm{SH}$.

formulation has been applied to different climates (e.g., Korty et al. 2012) and it differs from the form used by Emanuel (2010) only in that it incorporates the findings of Tippett et al. (2011), who showed that vorticity does not appear to be rate limiting outside of very low latitudes.

Figure 8a shows the ensemble mean GP for each hemisphere's storm season 6ka. It is broadly similar in structure to GP computed from model output for the present day (e.g., Camargo et al. 2007b), model output from predictions of the late twenty-first century (e.g., Emanuel et al. 2008), as well as that from reanalysis data (e.g., Emanuel 2010). Yet the similarity of these seasonal averages masks a notable shift in the seasonal cycle of the NH. Figures $8 \mathrm{~b}$ and $8 \mathrm{c}$ compare the GP (integrated over each hemisphere) for the preindustrial control (black) to the MH (white). Setting the coefficient $a$ to $1 / 1500$ yields a global total GP of 80 storms per year in this set of $0 \mathrm{ka}$ experiments. The annual total of the $\mathrm{NH}$ genesis potential (sum of all white bars in Fig. 8b) was 36.6 at $0 \mathrm{ka}$ and was slightly lower at $6 \mathrm{ka}$ (34.4). By contrast, the SH genesis potential was slightly higher at $6 \mathrm{ka}$

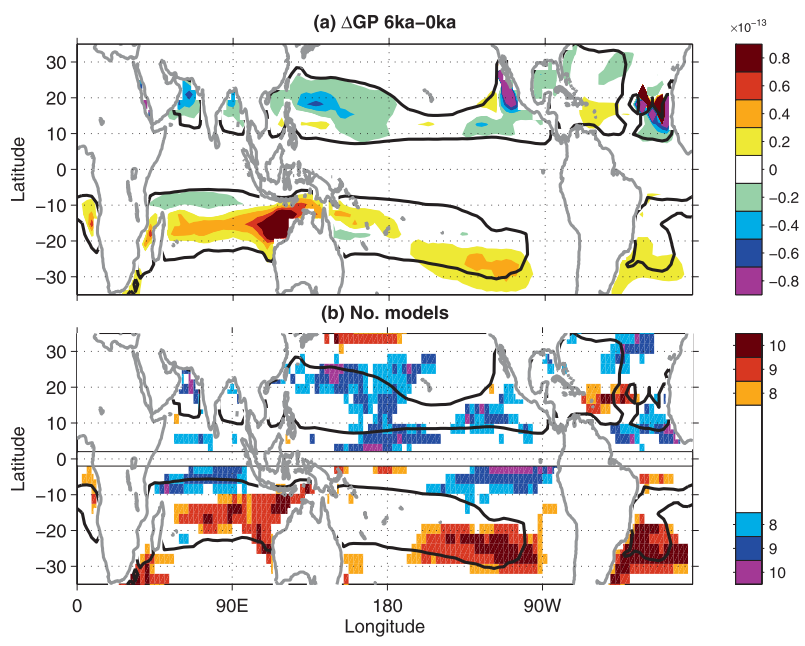

FIG. 9. (a) Difference in storm-season ensemble mean genesis potential between $6 \mathrm{ka}$ and $0 \mathrm{ka}$. (b) Number of individual models concurring with the sign change of the ensemble mean shown in (a).

(46.9) than in the control case (43.3); the slight increase in GP is fairly uniform across each month of the SH season.

During July and August, the GP at 6ka is substantially smaller than it is at $0 \mathrm{ka}$, while it is much higher at $6 \mathrm{ka}$ in October, which becomes the peak month of the year. The increase in October activity appears to arise from a delayed response in SST, which remains high during the autumn owing to the high heat capacity of water even though the perturbation in TOA radiation has faded away. During June-August (JJA), for example, Pacific SSTs were lower 6ka than today, while they were little changed between September and November (SON). There was also an autumnal increase in the Atlantic, where SSTs 6ka were little different during JJA but were slightly higher during SON than today.

The total GP is slightly lower 6ka than at $0 \mathrm{ka}$ in part of the western and eastern North Pacific, and generally higher in the SH Indian Ocean between $10^{\circ}$ and $20^{\circ} \mathrm{S}$ and in the South Pacific south of $20^{\circ} \mathrm{S}$ (Fig. 9a). The sign of the changes in these particular regions is generally common across most or all of the individual ensemble members (Fig. 9b). Elsewhere, there is little significant difference between the Mid-Holocene and preindustrial control. The slight rise in North Atlantic genesis potentials in Fig. 9a arises from a late season increase in the index during September and October. The sign change is weak and differs from model to model during July and August. Aside from this location, however, the pattern in Fig. 9a is generally insensitive to averaging over different subsets of months.

\section{d. Summary of Mid-Holocene results}

The main effect of higher TOA radiation during JASO was to repress $V_{\mathrm{PI}}$ by altering the thermal stability 
of the tropospheric column: temperatures in the marine boundary layer are very similar both $6 \mathrm{ka}$ and $0 \mathrm{ka}$ (cf. Fig. 6b), while those in the upper troposphere were warmer. In the $\mathrm{SH}$ season there is little difference in $V_{\mathrm{PI}}$ between $6 \mathrm{ka}$ and $0 \mathrm{ka}$ in the regions where it is largest, though $V_{\mathrm{PI}}$ is higher $6 \mathrm{ka}$ along the subtropical margin in response to the upper-level cooling induced by lower TOA radiation during JFMA. The cooler environment in the $\mathrm{SH}$ reduces $\chi$ during the storm season, and, in spite of slightly higher wind shears, the total GP increases slightly in each month. In the NH the GP seasonal cycle is delayed, largely owing to reduced $V_{\mathrm{PI}}$ from June to August, though the global annual total of GP differs by less than $2 \% 0 \mathrm{ka}$ and $6 \mathrm{ka}$, largely owing to an offset between the two hemispheres. Changes in the annual cycle of potential intensity and other aspects of tropical climate have been reported also in twenty-firstcentury climate change simulations (Biasutti and Sobel 2009; Seth et al. 2011; Sobel and Camargo 2011). We discuss some of the possible implications of our $\mathrm{MH}$ findings for paleotempestology proxies in the final section; next we examine the transient responses to largescale forcing in a simulation of the last millennium.

\section{Last millennium variability: Volcanism and the solar cycle}

The recently completed integration of the CESM simulation of the last millennium (Landrum et al. 2012) provides a long time series from which interannual variability in the factors can be examined. We defer a more thorough examination of this time series for subsequent work, as at the time of our analysis several modeling centers were still preparing LM runs for the next generation of PMIP. We take advantage of the CESM simulation now to explore how $V_{\text {PI }}$ varies during a period when greenhouse forcing was stable but surface conditions varied owing to solar and volcanic aerosol forcing.

The time series of potential intensity averaged over the storm in each basin ${ }^{5}$ is shown in Fig. 10. The mean for each basin is shown with a solid dark line and two standard deviations above and below are plotted with

\footnotetext{
${ }^{5}$ We define the basins to include the regions most prone to genesis today, though the variability and deviations from the mean are not particularly sensitive to the precise boundaries selected. For the analysis here we defined the Atlantic to include all ocean points south of $31^{\circ} \mathrm{N}$ and west of $70^{\circ} \mathrm{W}$ to the North American continent as well as the strip of ocean between $8.5^{\circ}$ and $20^{\circ} \mathrm{N}$ west of $20^{\circ} \mathrm{W}$. The eastern Pacific includes all points both west of Central America and between $5^{\circ}$ and $20^{\circ} \mathrm{N}, 85^{\circ}$ and $125^{\circ} \mathrm{W}$. The western Pacific was defined between $5^{\circ}$ and $20^{\circ} \mathrm{N}, 110^{\circ} \mathrm{E}$ and $180^{\circ}$. The $\mathrm{SH}$ is defined between $5^{\circ}$ and $20^{\circ} \mathrm{S}, 50^{\circ} \mathrm{E}$ and $130^{\circ} \mathrm{W}$.
}
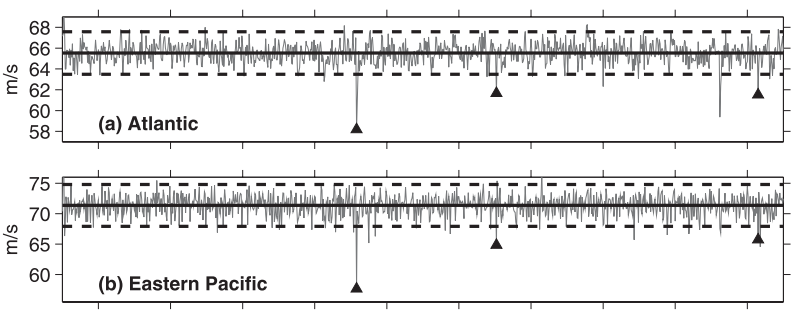

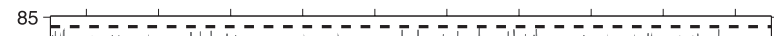

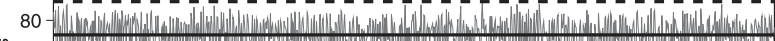

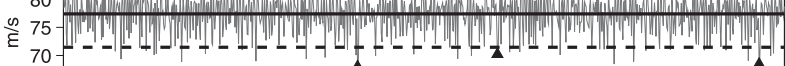
$65-$

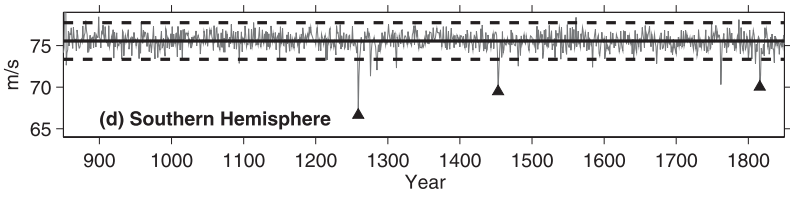

FIG. 10. Time series of storm-season potential intensity over the duration of the LM simulation for (a) North Atlantic, (b) eastern North Pacific, (c) western North Pacific, and (d) SH. Mean values are shown by the solid black line and two standard deviations above and below the mean are shown with dashed lines. Seasons following the major volcanic eruptions of 1258, 1452, and 1815 are highlighted with triangles.

dashed lines. There is a small window of interannual variability in each basin, and there is no long-term trend in any of the basins over the 10 centuries. The spread in interannual variability generally lies within a $5-10 \mathrm{~m} \mathrm{~s}^{-1}$ window in each basin, though it is larger in the western Pacific; Bister and Emanuel (2002) showed that the interannual variability of the global average of $V_{\mathrm{PI}}$ has a similar order of magnitude in late-twentieth-century reanalysis data. The largest deviations occur in years following volcanic eruptions, during which time $V_{\mathrm{PI}}$ values are substantially lower. The three largest eruptions occurred in 1258, 1452, and 1815; the seasons immediately following the eruptions are highlighted by triangles.

Figure 11 shows a comparison of the normal seasonal cycle in each basin to those from the years following the three strongest volcanic eruptions. Each year is more than two standard deviations lower in nearly all of the months at the peak of the storm season, with the largest event in 1258 producing the largest response. To understand why $V_{\mathrm{PI}}$ is so much lower in these years, consider the vertical structure of the temperature response shown in Fig. 12a, which shows the temperature anomalies (measured relative to the LM mean) from the year following the eruption in 1258. Tropospheric temperatures drop globally, and they are as much as $5^{\circ} \mathrm{C}$ colder in the deep tropics near $300 \mathrm{hPa}$. The response at higher altitudes, however, is strongly opposite: lower stratospheric temperatures rise substantially, and warming extends down to $150 \mathrm{hPa}$. Thus, lower and middle 
(a) Atlantic

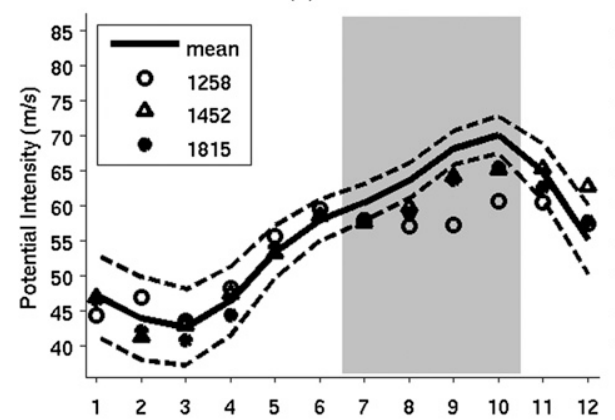

(c) Western N. Pacific

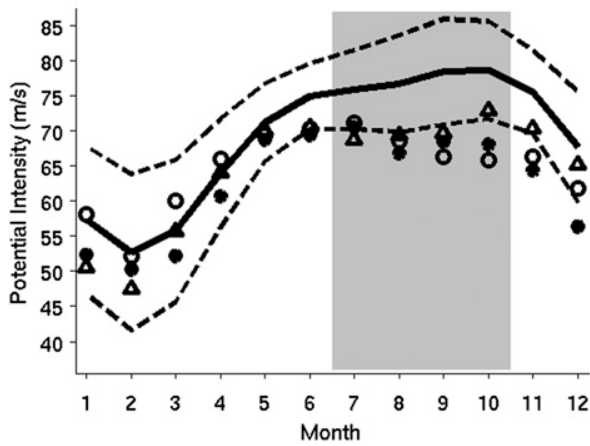

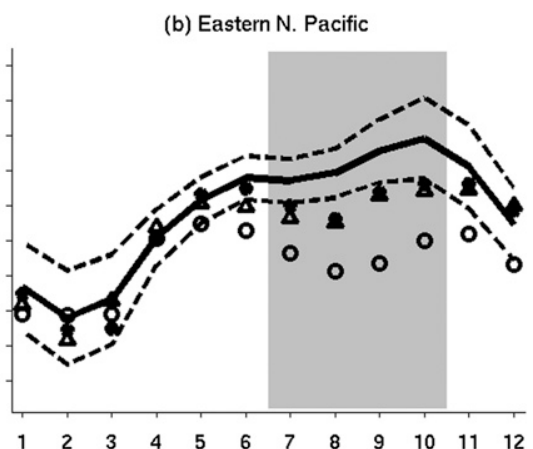

(d) Southern Hemisphere

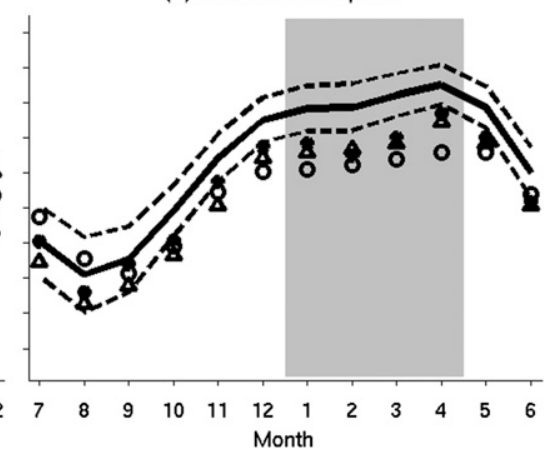

FIG. 11. Seasonal distribution of 1000-yr mean potential intensity (solid) and two standard deviations above and below (dashed) along with monthly values for the year following a major volcanic eruption. For (d) the Southern Hemisphere (the points begin in July of the year indicated (i.e., 1258, 1452, 1815) and continue through June of the following year (i.e., 1259, 1453, 1816). Gray band highlights the storm season in each hemisphere.

tropospheric temperatures fall appreciably following a major volcanic eruption like this. (The thermal response is similar following the eruptions of Kuwae and Tambora, but the amplitudes are smaller.) The vertical structure of this response alters the height to which convection can penetrate, in part owing to the strong warming near the tropopause that arises from sulfate aerosols (Evan 2012), which in turn lowers $V_{\mathrm{PI}}$. Note that this response is distinct from one that arises when cooling is more uniform. Korty et al. (2012) showed that the universal cooling at the LGM does not produce a monolithic response: several locations had higher potential intensity in the colder climate than in the warmer preindustrial control. Following strong volcanic eruptions, SSTs and tropospheric temperatures fall, but they rise at the tropopause. Like the response $6 \mathrm{ka}$, the vertical structure of warming or cooling has a controlling influence on the value of $V_{\mathrm{PI}}$.

Another external forcing that could affect the thermal stratification is the solar cycle. Gray et al. (2010) show that, because maxima in the solar cycle preferentially raise radiation at high frequencies (i.e., ultraviolet wavelengths), temperatures in the stratosphere and tropopause region respond more aggressively than at the surface. This upper-level warming has the potential to adversely affect $V_{\mathrm{PI}}$, and a series of papers (Elsner and Jagger 2008; Elsner et al. 2010; Hodges and Elsner 2010) have reported a detectable decline in actual intensities of the western part of the Atlantic basin and in landfall records of the United States in response to increased solar activity. Figure $12 \mathrm{~b}$ shows the actual differences in temperature between years at the peak of a solar cycle $\left(S_{\max }\right)$ and those at the base $\left(S_{\min }\right)$ during the satellite era in the National Centers for Environmental Prediction-National Center for Atmospheric Research (NCEP-NCAR) reanalysis (years 1979-2010). ${ }^{6}$ (Note that the contours represent amplitudes only onetenth of the values represented in Fig. 12a.) Though the

\footnotetext{
${ }^{6}$ We define $S_{\max }$ from the reanalysis product to be the average of the years 1979-82, 1988-92, and 1999-2002 while $S_{\min }$ is the average over years 1984-87, 1994-97, and 2005-10. (Given the short duration of this period, we average over several years near each extremum). The peak of each solar cycle included in $S_{\max }$ from LM is taken as the local maximum in the TSI time series shown in Fig. 2, and the years for $S_{\min }$ are taken to be the minima that follow them. Intervals with low-amplitude or absent cycles in years surrounding the various solar minima (shown in gray in Fig. 2) were excluded.
} 
(a)

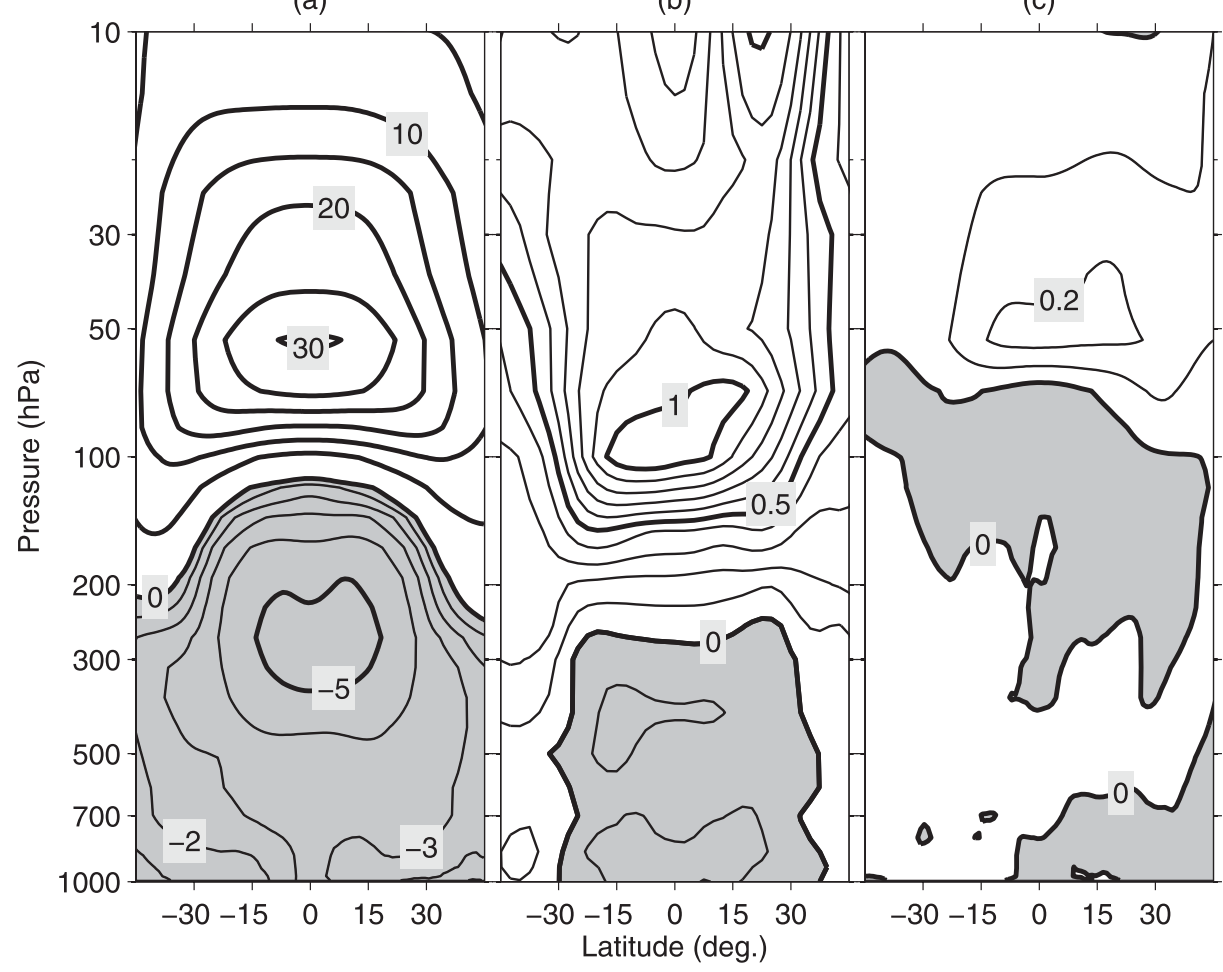

FIG. 12. (a) Annual and zonal mean temperature deviations from the LM mean following the 1258 volcanic eruption. (b) Difference in annual zonal mean temperatures between years at peak and base of solar cycle 1979-2010 NCEP-NCAR reanalysis. (c) As in (b) but from peak-base years of solar cycle in the LM simulation.

amplitude of the response is substantially smaller, the structure shares some qualitative similarities to one following volcanic eruptions: differential temperature responses between upper and lower levels have the potential to alter the thermal stability of the troposphere and hence affect $V_{\mathrm{PI}}$.

One advantage of this long time series is that it provides many solar cycles over which any response to it might be investigated. Yet the difficulties of using this simulation to investigate any influence it may have on the thermodynamic quantities are illustrated by comparing the response in the LM simulation (Fig. 12c) to the reanalysis data (Fig. 12b). The difference in temperature between years at the peak of a solar cycle $\left(S_{\max }\right)$ and those at the base $\left(S_{\min }\right)$ in the LM simulation is much weaker than that seen in the reanalysis data at all levels. A more critical shortcoming is the structural differences in the response: while reanalysis data shows that temperatures during $S_{\max }$ years are little different or slightly cooler in the middle and lower tropical troposphere, the increase in ultraviolet radiation raises upper-tropospheric and tropopause temperatures in the deep tropics (Fig. 12b; see Gray et al. 2010). The model response to solar activity, in contrast to reanalysis data, shows very little difference at all levels in the troposphere, and only a very weak rise in middle stratospheric temperatures. Thus it is not surprising that there is no statistically significant difference in the potential intensity in any ocean basin between $S_{\max }$ and $S_{\min }$ years. Because maxima in the solar cycle preferentially raise radiation at high frequencies (i.e., ultraviolet wavelengths), incorporating solar-related ozone changes might improve a model's vertical temperature response to the solar cycle.

\section{Summary and conclusions}

We investigated tropical cyclone genesis factors in a 10-member ensemble of Mid-Holocene simulations prepared for PMIP2. Variations in the precession of Earth's orbit are responsible for a seasonal redistribution of top-of-the-atmosphere incoming solar radiation that affects tropical temperatures at the peak of each hemisphere's storm season in opposite ways. During the MH, when Earth's closest approach to the sun occurred during September, TOA solar radiation was substantially higher $\left(\sim 20 \mathrm{~W} \mathrm{~m}^{-2}\right)$ during July-September, the peak months of $\mathrm{NH}$ tropical cyclone activity in the present-day climate. At the peak of the $\mathrm{SH}$ season, TOA solar radiation was as 
much as $\sim 20 \mathrm{~W} \mathrm{~m}^{-2}$ lower during the $\mathrm{MH}$ than it is at these latitudes today. SSTs are slower to respond to seasonal perturbations in radiation than are continental areas, where boundary layer moist entropy content rose in the NH summer and fell in the SH. Upper-level responses are more zonally homogeneous than the boundary layer response, and a consequence is that potential intensities respond in a manner that is anticorrelated with the sign of the TOA radiation perturbation.

The unequal vertical temperature response also causes the difference between boundary layer and midlevel entropies to rise or fall along with the TOA perturbation: midlevel entropies respond quickly to the anomalous solar radiation, while boundary layer values lag several months behind and are essentially unchanged from preindustrial-era levels at the peak of each hemisphere's storm season. This entropy difference has been identified as an important parameter in the gestation time required for incipient storms to develop. All else being equal, the more rapid response of the middle troposphere than at the surface should hinder development during the peak of the Northern Hemisphere while augmenting the favorability in the Southern Hemisphere. These responses are robust across the ensemble of models, though the amplitude of these deviations is small. There is also a shift in the seasonal distribution of genesis potential evident in the Northern Hemisphere response: by October, as the TOA perturbations rapidly fade out and the lagged surface response reaches a maximum, conditions become more favorable; potential intensity rises and vertical entropy differences decline.

We also examined a 1000-yr transient simulation forced with variable total solar irradiance (but lacking interactive ozone responses to solar activity) and volcanic eruptions. The time series of potential intensity exhibited no long-term trends over the millennium and generally lies within a window of interannual variability similar to that of the present era (Bister and Emanuel 2002). Major exceptions occur in years following substantial volcanic eruptions, where upper-tropospheric, tropopause, and lower-stratospheric temperatures rise substantially while the troposphere cools by several degrees. The eruptions of 1258, 1452 (Kuwae), and 1815 (Tambora) offer interesting case studies for the farreaching but short-lived effects on tropical cyclone thermodynamics: the nonuniform vertical response caps the level of neutral buoyancy to be at lower altitudes (higher pressures) and higher temperatures. Coupled with strongly reduced surface temperatures, potential intensities uniformly decline to levels several standard deviations below the long-term mean. Evan (2012) reported a reduction in North Atlantic tropical cyclone activity following two volcanic eruptions in the past 30 years, although both occurred concurrently with El Niño, which can also suppress activity via structurally similar thermal anomalies (Tang and Neelin 2004).

Though the last millennium simulation included a solar cycle, there are no solar-related ozone changes, and the temperature response differs in crucial ways from the pattern observed in reanalysis data. Elsner and Jagger (2008) detected a solar signal in the modern intensity records from a limited area in the western Atlantic basin, and the vertical structure of the response has a similar pattern but far weaker amplitude compared to what follows volcanic eruptions. Each of these mechanisms (orbital-induced radiation anomalies, volcanoes, solar cycle) has the capability to affect to varying degrees the thermodynamic environment by producing an opposite-signed temperature response between the lower and upper troposphere.

Yet, on a more practical level, perhaps the most important result is the broad stability of the various genesis parameters across the whole of the preindustrial Holocene. While the changes induced by the orbital variations can be explained and detected in the various thermodynamic quantities shown here, the magnitudes are generally small $\left(\sim 1-2 \mathrm{~m} \mathrm{~s}^{-1}\right.$ at most in the seasonal average potential intensity, with other areas indistinguishable from $0 \mathrm{ka}$ ). We expect that it may prove impossible to see many of these changes in any of the presently available paleotempestology proxies: for example, sand deposits from prehistoric hurricanes can be dated to an accuracy of within a few years, but there is no way to tell whether a shift in the seasonal cycle caused older deposits to be laid preferentially in October rather than August. (Though the possibility does exist that the seasonal shift in $\mathrm{NH}$ genesis potential reported here might affect the climatological distribution of storm tracks; we plan to investigate this in subsequent work.) Even if orbital variations caused a mild depression in Northern Hemisphere activity during the Mid-Holocene, the signal appears to be too faint to see by the last millennium, during which deviations induced by the slow drift in orbital parameters fade away into a range of interannual variability similar to the present climate. On the other hand, the responses in the year following strong volcanic eruptions show the potential for substantial if shortlived effects following a massive event.

Interpretations of proxies of past storm activity in both hemispheres imply that long intervals of intense storm activity have been interspersed with substantial lulls (Frappier et al. 2007; Nott et al. 2009; Lane et al. 2011), which some authors have speculated is related to ENSO (e.g., Donnelly and Woodruff 2007). Clement et al. (2000) showed that TOA radiation anomalies in 
the MH could reduce ENSO variability, a result supported by inferences from a lake sedimentary record (Conroy et al. 2008). Yet any relationship to tropical cyclone genesis is nontrivial, as prolonged periods dominated by a single phase of ENSO can alter the thermodynamic environment differently than high frequency transience would. El Niño events repress Atlantic activity, in part owing to the rapid warming of the atmosphere while surface temperatures there lag (Tang and Neelin 2004), but permanent El Niño conditions could have the opposite effect as Atlantic SSTs come into equilibrium with the warmer atmospheric conditions (cf. Federov et al. 2010). Thus, we believe this issue is likely to be complex and interesting, and it merits closer scrutiny.

Acknowledgments. We gratefully acknowledge the international modeling groups who made their data available for analysis and the Laboratoire des Sciences du Climat et de l'Environement (LSCE) for collecting, archiving, and distributing these simulations. The analyses were performed using the version of the PMIP2 database present on 8 June 2011; additional information is available online (http://pmip2.lsce.ipsl.fr). We thank Bette Otto-Bliesner for her advice and support on the project and three anonymous reviewers for useful comments and suggestions. We also thank Kerry Emanuel for making available his potential intensity algorithm and Ryan Zamora and Nick Adams for their assistance with data processing. The National Science Foundation supported this study through Grants ATM-1064013, ATM1064081, and ATM-1063837.

\section{REFERENCES}

Berger, A. L., 1978: Long-term variations of daily insolation and Quaternary climatic changes. J. Atmos. Sci., 35, 2362-2367.

Biasutti, M., and A. H. Sobel, 2009: Delayed Sahel rainfall and global seasonal cyclone in a warmer climate. Geophys. Res. Lett., 36, L23707, doi:10.1029/2009GL041303.

Bister, M., and K. A. Emanuel, 2002: Low frequency variability of tropical cyclone potential intensity 1 . Interannual to interdecadal variability. J. Geophys. Res., 107, 4801, doi:10.1029/ 2001JD000776.

Braconnot, P., and Coauthors, 2007a: Results of PMIP2 coupled simulations of the Mid-Holocene and Last Glacial Maximum Part 1: Experiments and large-scale features. Climate Past, 3, 261-277.

— of the mid-Holocene and Last Glacial Maximum - Part 2: Feedbacks with emphasis on the location of the ITCZ and mid- and high latitudes heat budget. Climate Past, 3, 279296.

Camargo, S. J., K. A. Emanuel, and A. H. Sobel, 2007a: Use of a genesis potential index to diagnose ENSO effects on tropical cyclone genesis. J. Climate, 20, 4819-4834.
- A. H. Sobel, A. G. Barnston, and K. A. Emanuel, 2007b: Tropical cyclone genesis potential index in climate models. Tellus, 59A, 428-443.

Clement, A. C., R. Seager, and M. A. Cane, 2000: Suppression of El Niño during the mid-Holocene by changes in the Earth's orbit. Paleoceanography, 15, 731-737.

Conroy, J. L., J. T. Overpeck, J. E. Cole, T. M. Shanahan, and M. Steinitz-Kannan, 2008: Holocene changes in eastern tropical Pacific climate inferred from a Galápagos lake sediment record. Quat. Sci. Rev., 27, 1166-1180.

DeMaria, M., 1996: The effect of vertical shear on tropical cyclone intensity change. J. Atmos. Sci., 53, 2076-2087.

Donnelly, J. P., 2005: Evidence of past intense tropical cyclones from backbarrier salt pond sediments: A case study from Isla de Culebrita, Puerto Rico, USA. J. Coastal Res., I42, 201-210.

— , and J. D. Woodruff, 2007: Intense hurricane activity over the past 5000 years controlled by El Niño and the West African monsoon. Nature, 447, 465-468.

Eady, J. A., 1976: The Maunder minimum. Science, 192, 1189-1202. Elsner, J. B., and T. H. Jagger, 2008: United States and Caribbean tropical cyclone activity related to the solar cycle. Geophys. Res. Lett., 35, L18705, doi:10.1029/2008GL034431.

,-- , and R. E. Hodges, 2010: Daily tropical cyclone intensity response to solar ultraviolet radiation. Geophys. Res. Lett., 37, L09701, doi:10.1029/2010GL043091.

Emanuel, K. A., 1986: An air-sea interaction theory for tropical cyclones. Part I: Steady-state maintenance. J. Atmos. Sci., 43, 585-605.

- 1987: The dependence of hurricane intensity on climate. Nature, 326, 483-485.

_ 1989: The finite-amplitude nature of tropical cyclogenesis. J. Atmos. Sci., 46, 3431-3456.

_ 1994: Atmospheric Convection. Oxford University Press, $580 \mathrm{pp}$.

_ 1995: The behavior of a simple hurricane model using a convective scheme based on subcloud-layer entropy equilibrium. J. Atmos. Sci., 52, 3959-3968.

— 2005: Reply. Nature, 438, E13, doi:10.1038/nature04427.

, 2010: Tropical cyclone activity downscaled from NOAACIRES reanalysis, 1908-1958. J. Adv. Model. Earth Syst., 2, doi:10.3894/JAMES.2010.2.1.

— , R. Sundararajan, and J. Williams, 2008: Hurricanes and global warming: Results from downscaling IPCC AR4 simulations. Bull. Amer. Meteor. Soc., 89, 347-367.

Evan, A. T., 2012: Atlantic hurricane activity following two major volcanic eruptions. J. Geophys. Res., 117, D06101, doi:10.1029/ 2011JD016716.

Federov, A. V., C. M. Breierly, and K. Emanuel, 2010: Tropical cyclones and permanent El Niño in the early Pliocene epoch. Nature, 463, 1066-1070.

Frappier, A., T. Knutson, K.-B. Liu, and K. Emanuel, 2007: Perspective: Coordinating paleoclimate research on tropical cyclones with hurricane-climate theory and modelling. Tellus, 59A, 529-537.

Gao, C., A. Robock, and C. Ammann, 2008: Volcanic forcing of climate over the past 1500 years: An improved ice core-based index for climate models. J. Geophys. Res., 113, D23111, doi:10.1029/2008JD010239.

Gray, L. J., and Coauthors, 2010: Solar influences on climate. Rev. Geophys., 48, RG4001, doi:10.1029/2009RG000282.

Gray, W. M., 1968: Global view of the origin of tropical disturbances and storms. Mon. Wea. Rev., 96, 669-700. 
Hodges, R. E., and J. B. Elsner, 2011: Evidence linking solar variability with US hurricanes. Int. J. Climatol., 31, 1897-1907, doi:10.1002/joc. 2196.

Jones, P. D., and M. E. Mann, 2004: Climate over past millennia. Rev. Geophys., 42, RG2002, doi:10.1029/2003RG000143.

Korty, R. L., and T. Schneider, 2007: A climatology of the tropospheric thermal stratification using saturation potential vorticity. J. Climate, 20, 5977-5991.

_ - S. J. Camargo, and J. Galewsky, 2012: Tropical cyclone genesis factors in simulations of the Last Glacial Maximum. J. Climate, 25, 4348-4365.

Landrum, L., B. L. Otto-Bliesner, E. R. Wahl, A. Conley, P. J. Lawrence, N. Rosenbloom, and H. Teng, 2012: Last millennium climate and its variability in CCSM4. J. Climate, in press.

Lane, P., J. P. Donnelly, J. D. Woodruff, and A. D. Hawkes, 2011: A decadally-resolved paleohurricane record archived in the late Holocene sediments of a Florida sinkhole. Mar. Geol. 287, 14-30.

Lighty, R. G., I. G. Macintyre, and R. Stuckenrath, 1982: Acropora palmata reef framework: A reliable indicator of sea level in the western Atlantic for the past 10,000 years. Coral Reefs, 1, 125130.

Lintner, B. R., and J. C. H. Chiang, 2007: Adjustment of the remote tropical climate to El Niño conditions. J. Climate, 20, 2544 2557.

Liu, K.-B., and M. L. Fearn, 1993: Lake-sediment record of late Holocene hurricane activities from coastal Alabama. Geology, 21, 793-796.

Mann, M. E., R. S. Bradley, and M. K. Hughes, 1999: Northern Hemisphere temperatures during the past millennium: Inferences, uncertainties, and limitations. Geophys. Res. Lett., 26, 759-762.

Mrowiec, A. A., S. T. Garner, and O. M. Pauluis, 2011: Axisymmetric hurricane in a dry atmosphere: Theoretical framework and numerical experiments. J. Atmos. Sci., 68, $1607-1619$

Nolan, D. S., 2011: Evaluating environmental favorability for tropical cyclone development with the method of pointdownscaling. J. Adv. Model. Earth Syst., 3, M08001, doi:10.1029/ 2011MS000063.

Nott, J., S. Smithers, K. Walsh, and E. Rhodes, 2009: Sand beach ridges record 6000 year history of extreme tropical cyclone activity in northeastern Australia. Quat. Sci. Rev., 28, 15111520.
Otto-Bliesner, B. L., E. C. Brady, G. Clauzet, R. Tomas, S. Levis, and Z. Kothavala, 2006: Last Glacial Maximum and Holocene climate in CCSM3. J. Climate, 19, 2526-2544.

Rappin, E. D., D. S. Nolan, and K. A. Emanuel, 2010: Thermodynamic control of tropical cyclogenesis in environments of radiative-convective equilibrium with shear. Quart. J. Roy. Meteor. Soc., 136, 1954-1971.

Royer, J.-F., F. Chauvin, B. Timbal, P. Araspin, and D. Grimal, 1998: A GCM study of the impact of greenhouse gas increase on the frequency of occurrence of tropical cyclones. Climatic Change, 38, 307-343.

Schmidt, G. A., and Coauthors, 2011: Climate forcing reconstructions for use in PMIP simulations of the last millennium (v1.0). Geosci. Model Dev., 4, 33-45.

Seth, A., S. A. Rauscher, M. Rojas, A. Giannini, and S. J. Camargo, 2011: Enhanced spring convection barrier for monsoons in a warmer world? Climatic Change, 104, 403-414.

Simmons, A. J., A. Untch, C. Jakob, P. Kållberg, and P. Undén, 1999: Stratospheric water vapour and tropical tropopause temperatures in ECMWF analyses and multi-year simulations. Quart. J. Roy. Meteor. Soc., 125, 353-386.

Sobel, A. H., and S. J. Camargo, 2011: Projected future changes in tropical summer climate. J. Climate, 24, 473-487.

Tang, B. H., and J. D. Neelin, 2004: ENSO influence on Atlantic hurricanes via tropospheric warming. Geophys. Res. Lett., 31, L24204, doi:10.1029/2004GL021072.

_ , and K. A. Emanuel, 2010: Midlevel ventilation's constraint on tropical cyclone intensity. J. Atmos. Sci., 67, 1817-1830.

Tippett, M. K., S. J. Camargo, and A. H. Sobel, 2011: A Poisson regression index for tropical cyclone genesis and the role of large-scale vorticity in genesis. J. Climate, 24, 2335-2357.

Vecchi, G. A., and B. J. Soden, 2007: Effect of remote sea surface temperature change on tropical cyclone potential intensity. Nature, 450, 1066-1070.

Woodruff, J. D., J. P. Donnelly, K. Emanuel, and P. Lane, 2008: Assessing sedimentary records of paleohurricane activity using modeled hurricane climatology. Geochem. Geophys. Geosyst., 9, Q09V10, doi:10.1029/2008GC002043.

$\longrightarrow$ - - and A. Okusu, 2009: Exploring typhoon variability over the mid-to-late Holocene: Evidence of extreme coastal flooding from Kamikoshiki, Japan. Quat. Sci. Rev., 28, 17741785 .

Xu, K., and K. A. Emanuel, 1989: Is the tropical atmosphere conditionally unstable? Mon. Wea. Rev., 117, 1471-1479. 